\title{
Methylglyoxal Levels in Human Colorectal Precancer and Cancer: Analysis of Tumor and Peritumor Tissue
}

\author{
Chu-Kuang Chou ${ }^{1,2, *,+} \oplus$, Po-Chun Yang ${ }^{1,+}{ }^{+}$, Pei-Yun Tsai ${ }^{3}$, Hsin-Yi Yang ${ }^{4}$, Kun-Feng Tsai ${ }^{5,6}$, \\ Tsung-Hsien Chen ${ }^{7} \oplus$, Kai-Sheng Liao ${ }^{8,9}$, Chi-Yi Chen ${ }^{1}$ and Jen-Ai Lee ${ }^{3}$
}

1 Division of Gastroenterology and Hepatology, Ditmanson Medical Foundation Chia-Yi Christian Hospital, Chiayi 60002, Taiwan; a250624545@hotmail.com (P.-C.Y.); 5137ccy@gmail.com (C.-Y.C.)

2 Clinical Trial Center, Ditmanson Medical Foundation Chia-Yi Christian Hospital, Chiayi 60002, Taiwan

3 School of Pharmacy, College of Pharmacy, Taipei Medical University, Taipei 11031, Taiwan; kellyrabbit324@gmail.com (P.-Y.T.); jenai@tmu.edu.tw (J.-A.L.)

4 Clinical Medicine Research Center, Ditmanson Medical Foundation Chia-Yi Christian Hospital, Chiayi 60002, Taiwan; cych13018@gmail.com

5 Gastroenterology and Hepatology Section, Department of Internal Medicine, An-Nan Hospital, China Medical University, Tainan 70965, Taiwan; tsai.kf@gmail.com

6 Department of Medical Sciences Industry, Chang Jung Christian University, Tainan 71101, Taiwan

7 Department of Internal Medicine, Ditmanson Medical Foundation Chia-Yi Christian Hospital, Chiayi 60002, Taiwan; cych13794@gmail.com

8 Department of Pathology, Ditmanson Medical Foundation Chia-Yi Christian Hospital, Chiayi 60002, Taiwan; 07455@cych.org.tw

9 Department of Nursing, Chung-Jen Junior College of Nursing, Health Sciences and Management, Da-Lin, Chiayi 62241, Taiwan

* Correspondence: vacinu@gmail.com; Tel.: +886-5-2765041

check for
updates

Citation: Chou, C.-K.; Yang, P.-C.; Tsai, P.-Y.; Yang, H.-Y.; Tsai, K.-F.;

Chen, T.-H.; Liao, K.-S.; Chen, C.-Y.; Lee, J.-A. Methylglyoxal Levels in Human Colorectal Precancer and Cancer: Analysis of Tumor and Peritumor Tissue. Life 2021, 11, 1319. https://doi.org/10.3390/life11121319

Academic Editor: Manuel Perucho

Received: 12 October 2021

Accepted: 26 November 2021

Published: 30 November 2021

Publisher's Note: MDPI stays neutral with regard to jurisdictional claims in published maps and institutional affiliations.

Copyright: (c) 2021 by the authors. Licensee MDPI, Basel, Switzerland. This article is an open access article distributed under the terms and conditions of the Creative Commons Attribution (CC BY) license (https:// creativecommons.org/licenses/by/ $4.0 /)$.
+ These authors contributed equally to this work.

\begin{abstract}
Colorectal cancer (CRC) is one of the most common cancers worldwide and its incidence is increasing; therefore, an understanding of its oncogenic mechanisms is critical for improving its treatment and management. Methylglyoxal (MGO) has a highly reactive aldehyde group and has been suggested to play a role in oncogenesis. However, no standardized data are currently available on MGO levels in colorectal precancerous and cancerous lesions. We collected 40 matched colorectal tumor and peritumor tissues from patients with low-grade dysplasia (LGD), high-grade dysplasia (HGD), and invasive cancer (IC). MGO levels increased between LGD, HGD, and IC tumor tissues $(215.25 \pm 39.69,267.45 \pm 100.61$, and $587.36 \pm 123.19 \mu \mathrm{g} / \mathrm{g}$ protein, respectively; $p=0.014)$. The MGO levels in peritumor tissue increased and were significantly higher than MGO levels in tumor tissue $(197.99 \pm 49.40,738.09 \pm 247.87,933.41 \pm 164.83 \mu \mathrm{g} / \mathrm{g}$ protein, respectively; $p=0.002)$. Tumor tissue MGO levels did not correlate with age, sex, underlying disease, or smoking status. These results suggest that MGO levels fluctuate in progression of CRC and warrants further research into its underlying mechanisms and function in tumor biology.
\end{abstract}

Keywords: human colorectal cancer; methylglyoxal; precancerous and cancerous; tumor and peritumor tissue

\section{Introduction}

Colorectal cancer (CRC) is one of the most important public health concerns and results in the most cancer-related deaths worldwide [1]. A majority of the adenomas of CRCs develop from precancerous adenoma with low-grade dysplasia (LGD), which typically progress to high-grade dysplasia (HGD) and invasive cancer (IC) [2]. Inflammatory bowel disease is an important risk factor that is involved in the development of CRC, which is a multifactorial disease resulting from a combination of genetic, environmental, and lifestyle risk factors $[3,4]$. 
The formation and accumulation of methylglyoxal (MGO) is associated with agerelated diseases such as atherosclerosis, cancer, metabolic syndrome and neurodegenerative disorders [5]. Fat oxidation and glyceraldehyde 3-phosphate pathways and glycolysis pathways may be important sources of MGO production [6]. MGO is the most potent glycating agent in humans and reacts with proteins to generate advanced glycation end products (AGEs) [7], resulting in protein dysfunction, AGE receptor activation, chronic inflammation, oxidative stress, and oncogenesis [8]. The accumulation of AGEs is due to cellular processes that cause mitochondrial dysfunction, genomic instability, loss of proteostasis, inflammation, and cellular senescence [9]. In addition, MGO reacts with DNA to form glycated DNA, which generates excessive reactive oxygen species (ROS) [10], leading to cell toxicity, apoptosis or necrosis [11]. MGO abduction is higher in human CRC tissue than in normal tissue $[12,13]$ and may inhibit cancer growth via eliciting direct toxicity, promoting oncogenesis by enhancing AGEs, or other unknown pathways [14,15]. Cancer cells alter their metabolism to enhance proliferation, growth and survival by increasing their energy production from glycolysis [16], known as the Warburg effect, which results in MGO accumulation.

However, molecular analyses of the association between MGO and CRC have yielded contradictory results [17-20]. CRC cells with different MGO concentrations reduced cell viability in a time- and dose-dependent manner, induced apoptosis, and inhibited cell migration and invasion [19]. The g cancer cell growth was reduced in the peritoneum of MGO-treated murine CRC model $[19,20]$. Glyoxalase I (GLOI), which catalyzes MGO metabolism, is associated with the progression of human malignancies and MGO exhibited a greater inhibitory effect when combined with short hairpin RNAs (shRNAs), silencing GLOI [20]. Furthermore, shRNA-mediated GLOI depletion without MGO administration inhibited CRC proliferation and migration, induced cell line apoptosis, and inhibited tumor growth in a murine model [21]. Conversely, Chiavarina et al., [12] found that an increased accumulation of MGO adducts can cause an inflammatory response, which is significantly related to tumor-promotion in patients with advanced CRC. In addition, intraperitoneal MGO administration in BALB/c mice with CT26 isografts enhanced CRC growth [18]. MGO-induced carbonyl stress can also enhance the degree of malignancy of tumor cells and increased the expression of tumor proliferation and migration markers CD29, CD44, and Msi-1 [18].

To date, the variation in the MGO levels throughout oncogenesis in human CRC tissue has not been evaluated. Previous resection techniques for large, early colorectal neoplasms (LGD and HGD) resulted in small, fragmented pieces, making it difficult to distinguish between normal and cancerous tissue and quantify their respective MGO levels. However, the development of endoscopic submucosal dissection techniques allows for large early colorectal neoplasms to be resected with adequate peritumor tissue [22], which permits the analysis of MGO levels in both tumor and peritumor tissue. In this study, we quantified MGO levels from precancerous to cancerous colorectal lesions, providing insight into its potential role in colorectal carcinogenesis, and possible pathogenic mechanisms.

\section{Materials and Methods}

\subsection{Patient Selection and Data Collection}

Patients with colorectal neoplasms, including pre-cancerous and cancerous lesions, were enrolled between June 2014 and June 2016. A total of 40 primary tumors were collected from patients diagnosed with CRC who underwent surgery at Chiayi Christian Hospital (Chiayi, Taiwan). The study was approved by the Institutional Review Board of Chiayi Christian Hospital (protocol code 102057). Demographic data, including age, gender, diabetes mellitus, hypertension, and smoking history, were collected by reviewing patient charts and from questionnaires. CRC staging was carried out according to the 7th edition American Joint Committee on Cancer (AJCC) criteria [23] and determined according to pathological diagnosis for patients whose cancerous lesions were fully resected. 


\subsection{Tissue Collection}

Colorectal tumor and peritumor mucosa tissue were collected from forty participants during scheduled procedures conducted according to the current guidelines for the management of colorectal neoplasms [24].

Endoscopic submucosal dissection was used for the resection of LGD, HGD, and T1 IC (invasive cancer) tumor tissues, since there was an adequate peritumor safety margin $[22,25]$ (Figure 1a). The colon wall consists of an inner mucosal layer (location of early colorectal neoplasms), an outer muscle layer, and a submucosal layer. After defining the resection area with an adequate safety margin, the submucosal layer was dissected to separate the mucosa from the muscle layer, enabling the resection of a large area of the mucosa and submucosa consisting of both the tumor and peritumor safety margins. The lateral peritumor safety margin was approximately $0.5-1 \mathrm{~cm}$ (Figure 2). If the IC was not suitable for endoscopic submucosal dissection, we used biopsy forceps to directly resect the tumor and peritumor tissue.

Once the lesion had been resected, small sections of the tumor and peritumor tissue were dissected; washed with normal saline to remove blood, stool, and other contaminants; placed into Eppendorf tubes on ice; and stored at $-80{ }^{\circ} \mathrm{C}$ until further analysis. Most of the main lesions were stored in $4 \%$ formaldehyde solution and sent to the pathology department for further histopathological diagnosis.

(a)
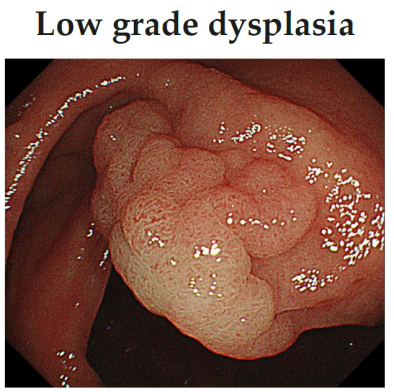

(b)

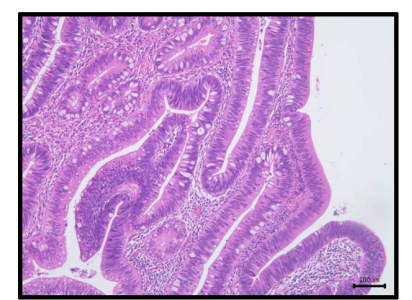

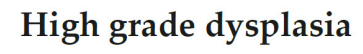
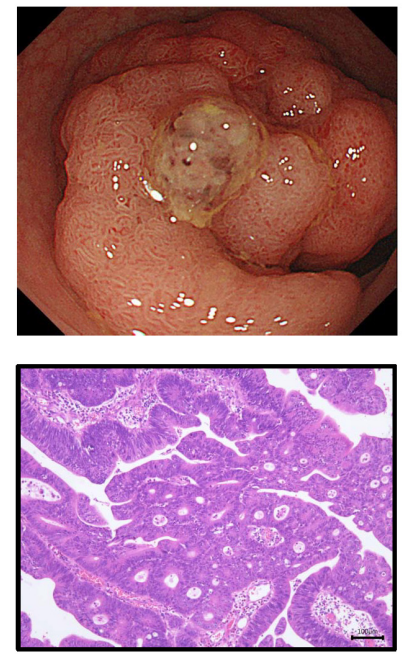

Invasive cancer
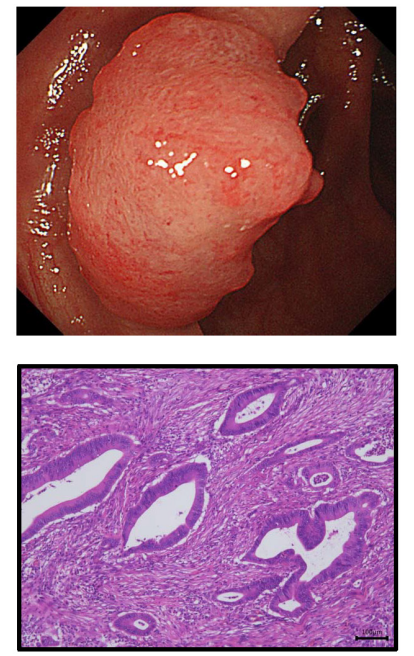

Figure 1. Classification of colorectal tumor mucosa tissues by (a) white-light imaging endoscopy, and (b) Hematoxylin and eosin (H\&E) staining of tumor mucosa tissue samples. Tumor tissues are classified as low-grade dysplasia, high-grade dysplasia, and invasive cancer (T1 colorectal cancer), sequentially. Scale bar $=100$ microns.

\subsection{Pathology}

Hematoxylin and eosin (H\&E) staining was used on all dissected tissue samples to determine standard pathologic staging (i.e., tumor type, differentiation, budding, grade, invasion depth, lymphovascular invasion, and perineural invasion). Adenoma with LGD, HGD, or IC was diagnosed according to the World Health Organization's classifications [26] (Figure 1b). Adenoma was defined as dysplastic endothelium, low- or high-grade dysplasia were defined by both cytological and architectural features, and invasive cancers were defined by the presence of neoplastic glands penetrating from the muscularis mucosa into the submucosa. 

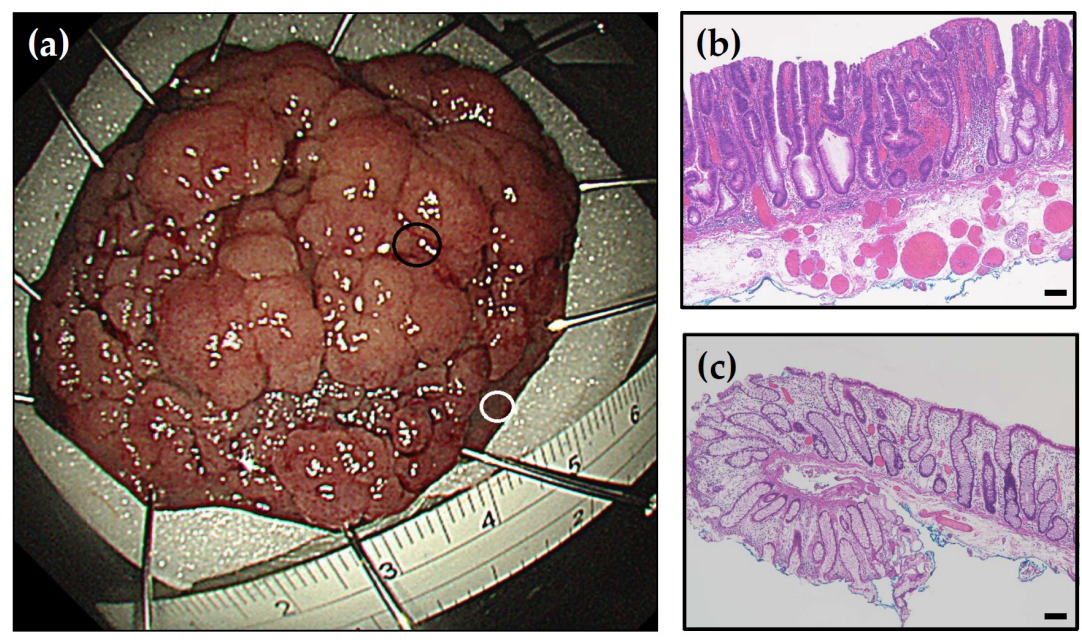

Figure 2. Endoscopic submucosal dissection. (a) Tumor tissue was dissected from the specimen (black circle) and peritumor tissue was identified and collected (white circle). (b) Hematoxylin and eosin (H\&E) staining of tumor sections. (c) H\&E staining of peritumor tissue sections. Scale bar $=100$ microns.

We followed Vienna classification [27]. Dysplasia was defined as neoplastic epithelial proliferation with the potential to become invasive. A distinction between LGD and HGD was conventionally based on features as whether the neoplastic nuclei were limited primarily to the lower or upper halves of the cells in the glands. The LGD looks close to normal tissue with some epithelial proliferation. The picture of LGD showed stratification of nuclei that do not reach the luminal cell surface, mildly elongated and dysplastic nuclei and mitotic activity with mild loss of polarity.

\subsection{Total Protein Assay}

Human colonic tissue was homogenized with phosphate buffered saline (PBS) (SigmaAldrich, St. Louis, MO, USA), diluted four-fold, and subjected to analysis with a commercial protein assay kit (Bio-Rad, Hercules, CA, USA) according to the manufacturer's instructions. A working reagent was prepared with Bicinchoninic Acid (BCA) reagents $A$ and $B$ at a ratio of 50:1 (v/v). A stock bovine serum albumin (BSA) solution $(2 \mathrm{mg} / \mathrm{mL})$ was diluted to 25 , $125,250,750,1,250,1,750$, and $2,000 \mu \mathrm{g} / \mathrm{mL}$ to produce a standard curve. Both the sample and standards solution $(25 \mu \mathrm{L})$ were placed into Eppendorf tubes with $200 \mu \mathrm{L}$ working buffer, shaken for $30 \mathrm{sec}$, and incubated at $37^{\circ} \mathrm{C}$ for $30 \mathrm{~min}$ and at room temperature for $3 \mathrm{~min}$. The sample and standard solution $(200 \mu \mathrm{L})$ was then transferred onto a 96 well plate and its optical density was measured at $562 \mathrm{~nm}$.

\subsection{Quantification of MGO Concentrations by Fluorescent HPLC Analysis}

Tissue MGO levels were determined using a fluorescent high performance liquid chromatography (HPLC) analysis, as described previously [28]. All HPLC equipment was purchased from Hitachi (Tokyo, Japan). Colon homogenates were added to $2 \mu \mathrm{L}$ of ammonium chloride buffer ( $\mathrm{pH}$ 10; Sigma-Aldrich, St. Louis, MO, USA) to create an alkaline environment for derivatization. The derivative reagent (50 $\mu \mathrm{L}$ of $7.5 \times 10^{-4} \mathrm{M}$ 5,6-diamino-2,4-dihydroxy-pyrimidine; Sigma-Aldrich, St. Louis, MO, USA) was added, the mixture was incubated at $60{ }^{\circ} \mathrm{C}$ for $30 \mathrm{~min}$ in the dark, and the reaction was stopped by adding $500 \mu \mathrm{L}$ of $0.01 \mathrm{M}$ citric acid buffer (pH 6; Sigma-Aldrich, St. Louis, MO, USA). The mixture was vortexed, spun down, incubated on ice for $10 \mathrm{~min}$, and centrifuged at $12,000 \mathrm{rpm}$ for $10 \mathrm{~min}$ at $4{ }^{\circ} \mathrm{C}$. The supernatant was filtered $(0.45 \mu \mathrm{m})$ to remove impurities, layered to a ODS column $(250 \mathrm{~mm} \times 4.6 \mathrm{~mm}$ i.d.; 5 - $\mu \mathrm{m}$ particle size; Biosil Chemical, Taipei, Taiwan), separated at $33^{\circ} \mathrm{C}$, with acetonitrile (Merck KGaA, Darmstadt, Germany) and $0.01 \mathrm{M}$ citric acid buffer (3:97, v/v; Sigma-Aldrich, St. Louis, MO, USA) as the mobile 
phase, at a flow rate of $0.7 \mathrm{~mL} / \mathrm{min}$, and excitation/emission wavelengths of $330 / 500 \mathrm{~nm}$. All samples were analyzed within $24 \mathrm{~h}$.

Various concentrations $(25,50,100,200,400,600,800$, and $1000 \mu \mathrm{g} / \mathrm{L})$ of MGO $(20 \mu \mathrm{L}$ of $40 \%$ aqueous solution; Sigma-Aldrich, St. Louis, MO, USA) were used to produce a calibration curve plotted according to the peak area ratio of MGO. Tissue samples were added to the different concentrations of the $20 \mu \mathrm{L}$ MGO standard $(0,300$, and $600 \mu \mathrm{g} / \mathrm{L})$ and analyzed by fluorescent HPLC described above. Precision was determined using relative standard deviation (RSD) and accuracy was expressed in terms of calculated recovery.

\subsection{Immunohistochemistry}

Resected MGO colorectal neoplasm were sliced into 3- $\mu \mathrm{m}$ sections, embedded in paraffin, and analyzed by immunohistochemical staining to determine MGO localization. LGD, HGD, or IC tumor tissue sections were deparaffinized with xylene (Sigma, St. Louis, MO, USA), rehydrated in a series of alcohol (Sigma, St. Louis, MO, USA), and rinsed with $\mathrm{diH}_{2} \mathrm{O}$ and $1 \times$ Tris-buffered saline (TBS), following standard protocol. Antigen retrieval was performed in antigen unmasking solutions (Vector, Burlingame, CA, USA), samples were placed in a pressure cooker (solution temperature $\approx 120^{\circ}$ ) for $1 \mathrm{~min}$, and run under cold water for $14 \mathrm{~min}$.

After blocking the samples with $3 \% \mathrm{H}_{2} \mathrm{O}_{2}$ (Sigma, St. Louis, MO, USA) for $10 \mathrm{~min}$, the slides were washed with PBS. Thereafter, the slides were incubated with Blocking Reagent A (Nichirei Biosciences, Tokyo, Japan) for $60 \mathrm{~min}$ at room temperature. Anti-MGO monoclonal antibody (STA-001, Cell biolabs, San Diego, CA, USA) was diluted 50-fold and incubated with the samples overnight. The samples were then washed with PBS and incubated with Blocking Reagent B (Nichirei Biosciences, Tokyo, Japan) for $10 \mathrm{~min}$ at room temperature. The samples were then incubated with a secondary antibody (reduced Fab antibody fragments of goat anti-mouse IgG conjugated with a labeled polymer prepared by combining amino acid polymer with multiple molecules of peroxidase) for $10 \mathrm{~min}$ at room temperature. Thereafter the samples were dried, co-cultured with chromogen/substrate reagent (Thermo, Waltham, MA, USA), and incubated in the dark at room temperature for $10 \mathrm{~min}$. Counterstaining with hematoxylin was performed and a quantitative image analysis of the immunohistochemical stains was performed by pathologists, and the proportion of cytoplasmic and nuclear MGO in tumor cells was determined.

\subsection{Statistical Analyses}

All statistical analyses were performed using SPSS for Windows version 21.0 (IBM Corp., Armonk, NY, USA). Continuous variables were expressed as means \pm standard error, and categorical data were expressed as percentages. Comparisons of continuous data were made between groups using Mann-Whitney U tests, and categorical data were compared using the chi-square test or Fisher's exact test. Multiple comparisons were made using the Kruskal-Wallis test with Dunn's post-hoc test. Correlations between parameters were calculated using Pearson's correlation coefficient and univariate regression analysis with the least-squares method. Statistical significance was set at $95 \%(p<0.05)$.

\section{Results}

\subsection{Demographic Data for the Different Groups of Colorectal Neoplasms}

In total, forty patients were enrolled in this study and divided into three groups according to their pathology: adenoma with LGD $(n=11)$, adenoma with HGD $(n=14)$, and IC $(n=15)$. Six out of the fifteen patients with invasive cancer were classified as stage I, four as stage II, and five as stage III. There were no significant differences in age, sex, diabetes, hypertension, or smoking status between the groups (Table 1). 
Table 1. Study population demographics.

\begin{tabular}{cccccc}
\hline & Low-Grade Dysplasia & High-Grade Dysplasia & Invasive Cancer & Total & $p$-Value * \\
\hline Number & 11 & 14 & 15 & 40 & 0.408 \\
Age (years) & $67.91 \pm 3.17$ & $70.50 \pm 2.81$ & $66.20 \pm 2.83$ & $68.18 \pm 1.67$ & 0.830 \\
Sex & & & & $4(26.67)$ & $13(32.50)$ \\
Female & $7(36.36)$ & $5(35.71)$ & $11(73.33)$ & $27(67.50)$ & $5(12.50)$ \\
Male & $1(63.64)$ & $9(64.29)$ & $1(6.67)$ & 0.448 \\
Diabetes mellitus & $2(18.09)$ & $3(21.43)$ & $3(20.00)$ & $8(20.00)$ & 0.980 \\
Hypertension & $1(9.09)$ & $3(21.43)$ & $5(33.33)$ & $8(20.00)$ & 0.250 \\
Smoking & $2(14.29)$ & & & & \\
\hline
\end{tabular}

* Non-parametric data (Kruskal-Wallis test), post-hoc test: Dunn test, chi-square test. Continuous data: mean \pm SEM; categorical data: number (proportion).

\subsection{Fluorescent HPLC Results and Method Validation in Human Colon Samples}

The MGO peak appeared at $26 \mathrm{~min}$ and the standard curve indicated a good linear relationship $\left(R^{2}=0.9997\right)$. All chromatograms for colorectal LGD, HGD, and IC samples are shown in Figure 3. The precision (RSD) and accuracy (recovery) of MGO determination in human colon samples are shown in Table S1. Intra-assay values indicated an accuracy of $115.14-119.93 \%$ and a precision of $2.70-10.84 \%$ (RSD) for triplicate measurements, whilst inter-assay values indicated an accuracy of $106.49-113.22 \%$ and a precision of $2.57-7.98 \%$ (RSD) for triplicate measurements.

(a)

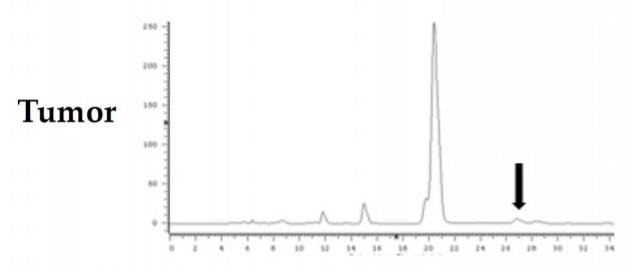

(b)

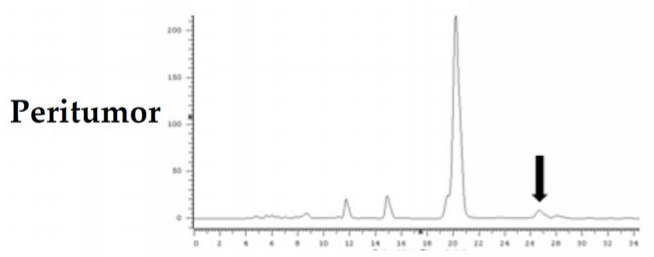

Low grade dysplasia (c)

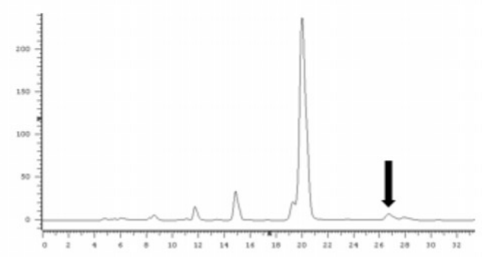

(d)

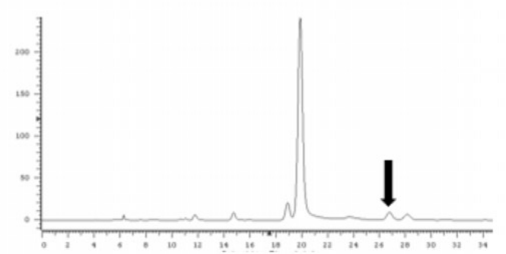

High grade dysplasia (e)

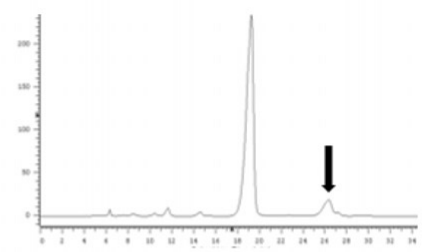

(f)

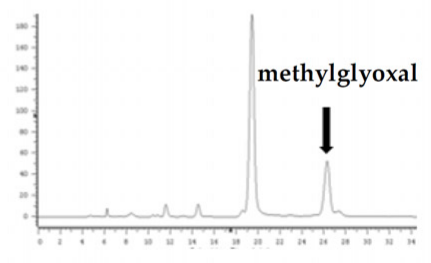

Invasive cancer

Figure 3. Detection of methylglyoxal in various stages of colorectal cancer using fluorescent high performance liquid chromatography: (a) low-grade dysplasia tumor tissue, (b) low-grade dysplasia peritumor tissue, (c) high-grade dysplasia tumor tissue, (d) high-grade dysplasia peritumor tissue, (e) invasive cancer tissue, (f) invasive cancer peritumor tissue. Arrow indicates the methylglyoxal peak. The reaction between methylglyoxal and the derivatization agent (DDP) in the human colorectal tissue produces a fluorescent product, which allows low concentrations of methylglyoxal to be detected.

\subsection{MGO Levels in Tumor and Peritumor Human Colon Tissue}

MGO levels increased between LGD, HGD, and IC tumor tissues $(215.25 \pm 39.69$, $267.45 \pm 100.61$, and $587.36 \pm 123.19 \mu \mathrm{g} / \mathrm{g}$ protein, respectively; $p=0.014)$. Interestingly, MGO levels between LGD, HGD and IC peritumor tissues increased and were significantly higher than MGO levels in tumor tissues $(197.99 \pm 49.40,738.09 \pm 247.87$, $933.41 \pm 164.83 \mu \mathrm{g} / \mathrm{g}$ protein, respectively; $p=0.002$; Figure 4). MGO levels in tumor tissue from the LGD group were slightly lower than that of the peritumor tissue in the LGD group $(215.25 \pm 39.69 \mu \mathrm{g} / \mathrm{g}$ vs $197.99 \pm 49.40 \mu \mathrm{g} / \mathrm{g}$ of protein, respectively; $p=0.491)$. MGO levels in HGD and IC tumor tissues were substantially lower than in peritumor 
tissues $(738.09 \pm 247.88 \mathrm{vs} 267.45 \pm 100.61 \mu \mathrm{g} / \mathrm{g}$ of protein, respectively; $p=0.089$; and $933.41 \pm 164.83$ vs $587.36 \pm 123.19 \mu \mathrm{g} / \mathrm{g}$ of protein, respectively; $p=0.085$ ) (Figure 4 ).

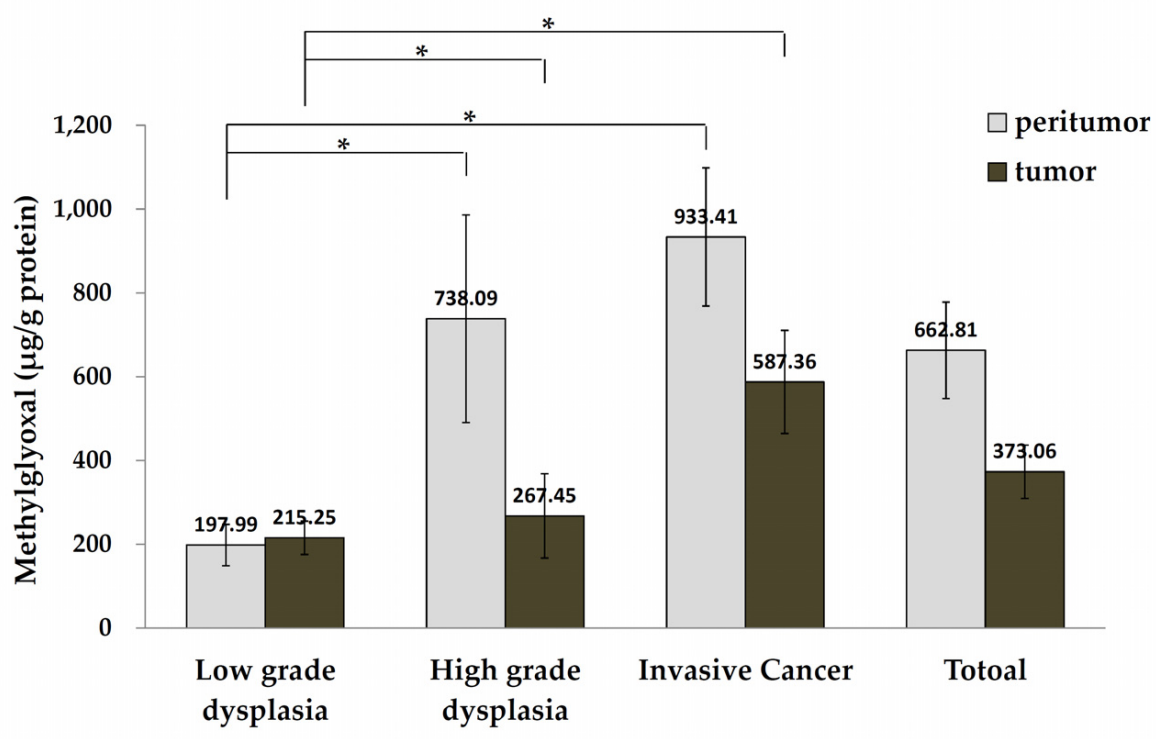

Figure 4. Comparison of methylglyoxal levels in tumor and peritumor tissue from patients with low-grade dysplasia, high-grade dysplasia, and invasive cancer $\left({ }^{*} p<0.05\right)$. Nonparametric statistics (Kruskal-Wallis test), post-hoc test: Dunn test.

\subsection{Evidence of MGO Dicarbonyl Stress in Human CRC Tumors}

IHC staining results indicated that MGO levels in LGD, HGD and IC tumor tissues slightly increased gradually (Figure 5). The proportion of cytoplasm stained by MGO in LGD, HGD, and IC tumor tissues were $0.01 \pm 0.02,0.05 \pm 0.07$, and $0.07 \pm 0.12$, respectively $(p=0.138)$. Additionally, the proportion of nuclei stained by MGO in LGD, HGD, and IC tumor tissues were $0.20 \pm 0.31,0.34 \pm 0.37$ and $0.45 \pm 0.33$, respectively $(p=0.237)$. There was a positive correlation between the proportion of cytoplasmic staining and MGO levels $(0.509, p<0.01)$.

(a)

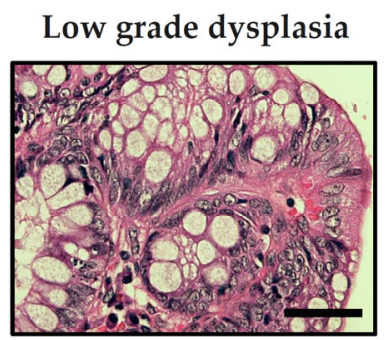

(b)

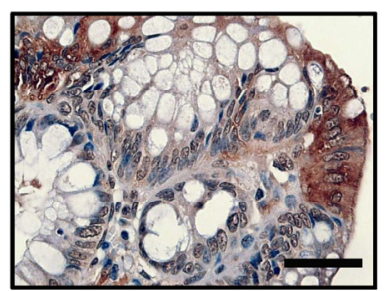

High grade dysplasia
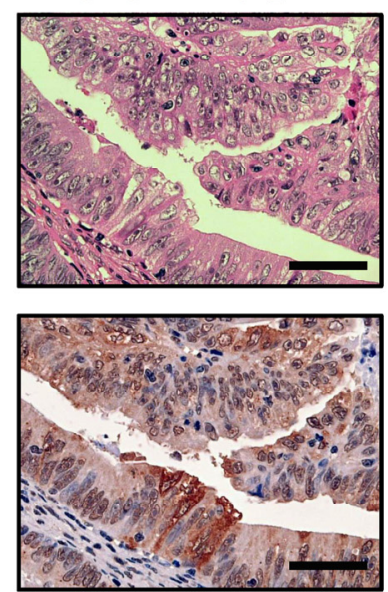

Invasive cancer
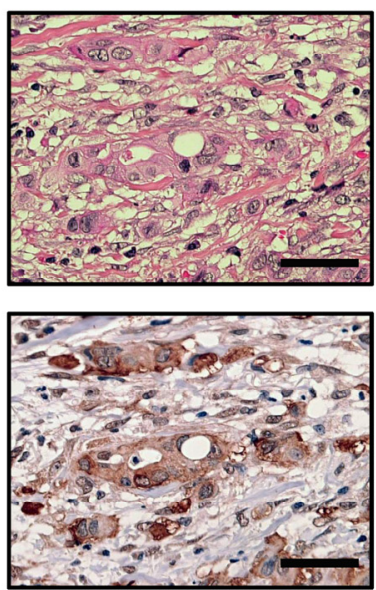

Figure 5. Evaluation of methylglyoxal (MGO) levels in low-grade dysplasia, high-grade dysplasia, and invasive cancer (T1) colorectal cancer tissues: (a) Hematoxylin and eosin (H\&E) staining, (b) Immunohistochemical staining. Scale bar $=100$ microns. 


\subsection{Association of Tissue MGO Levels with Age and Underlying Diseases}

Tissue MGO levels were not related to age in either the peritumor tissue ( $\beta$-value of linear regression $=0.12, p=0.461)$ or tumor tissue $(\beta$-value $=0.01, p=0.945$; Figure 6$)$. Moreover, MGO levels in both groups did not differ according to diabetes, hypertension co-morbidity, smoking status, or sex.

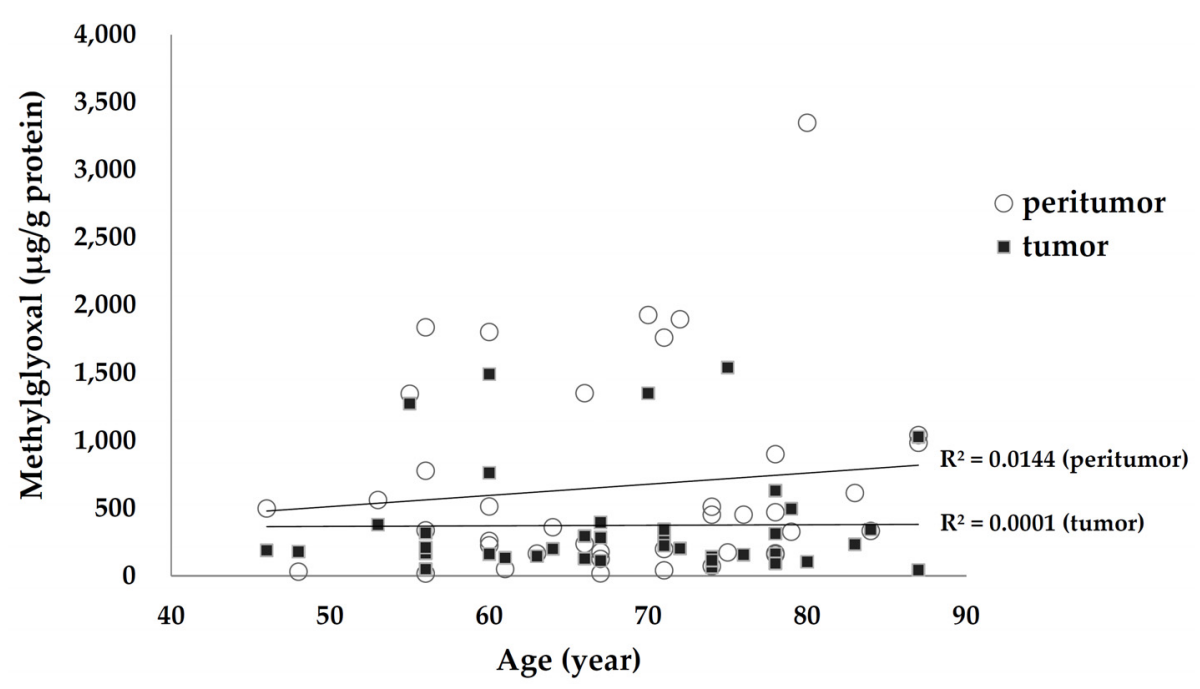

Figure 6. Comparison between age and methylglyoxal levels in tumor and peritumor tissue.

\section{Discussion}

Our results provide novel insights into the function of MGO in colorectal oncogenesis, which could help identify potential treatment targets or preventive strategies for patients with early-stage CRC. MGO levels increased between LGD, HGD, and IC tumor tissues, and MGO levels in peritumor tissues were significantly higher than in tumor tissues. MGO levels in tumor tissues did not correlate with age, sex, underlying disease, or smoking status.

Patients with LGD have a lower risk of developing cancer than patients with HGD. LGD resolves in $38-75 \%$ of the cases and persists in $19-50 \%$ of cases [29]. Among the patients with LGD, $0-23 \%$ show malignant changes within an average of 10-48 months from initial diagnosis [30-34]. Additionally, patients with LGD have a lower risk of malignant transformation (3-9\%) [32,33]. In a recent Dutch national study, it was found that recurrent LGD at a follow-up colonoscopy is a risk factor for developing advanced neoplasia in patients with inflammatory bowel disease (the incidence rate of recurrent LGD vs nonrecurrent LGD: 22.7 vs 14.0 per 1,000 patient-years) [35]. Previous resection techniques for large early colorectal neoplasms (LGD and HGD) resulted in small, fragmented pieces, making it difficult to distinguish between peritumor and tumor tissue and quantify their respective MGO levels. However, the development of endoscopic submucosal dissection techniques allows large early colorectal neoplasms to be resected with adequate peritumor tissue [22], permitting the analysis of MGO levels in both tumor and peritumor tissue. Here, we quantified MGO levels in colorectal precancerous to cancerous lesions, providing insight into its potential role in colorectal carcinogenesis and a new tool to understand its underlying mechanisms.

Many cytokines that are produced by intestinal immune cells during or in response to local inflammation in the colon and rectum, can stimulate complex interactions between different cell types in the intestinal environment, leading to acute inflammation [36]. Inflammation has been shown induce the occurrence and progression of CRC [37]. MGO accumulation can promote inflammation and contribute to endothelial dysfunction. The dual-role of MGO in tumor progression and its anti-cancer effect was initially attributed to MGO cytotoxicity, and its subsequent pro-tumorigenic effect was observed in several types of cancer, including CRC [38]. Normal cells use mitochondrial oxidative respiration 
with oxygen availability to produce energy. However, cancerous cells have a high rate of glucose uptake, lactate secretion and oxygen availability. One of the main differences in cancer cell metabolism is represented by their preference to use anaerobic glycolysis to produce adenosine triphosphate (ATP), but this process produces less ATP than glucose fermentation [39]. Cancer cells prefer glucose fermentation to lactate because this process is 10-100 times faster than complete mitochondrial glucose oxidation [40]. Compared with glucose, glucose-derived glycolysis intermediates, especially MGO, produce much more glycated proteins in a faster way [15]. This leads to AGE accumulation and receptor for AGE (RAGE) pathway activation which contributes to cancer pathogenesis by fostering tissue and cellular dysfunction [41]. This is the first study to compare human colorectal cancerous and precancerous tissue MGO levels, and our results indicated MGO levels is higher in peritumor tissue than in tumor tissue. Moreover, MGO levels clearly increased in a sequence corresponding to oncogenesis, during the progression of LGD to HGD to IC, suggesting that MGO plays a role in cancer progression. HPLC results can clearly distinguish the difference in MGO accumulation levels between LGD, HGD and IC segments. In the IHC stains, we observed a trend in MGO cytoplasmic staining in LGD, HGD and IC segments. However, due to the limited number of cases, there was no statistically significant difference in the proportion of MGO-stains between LGD, HGD and IC sections in the cytoplasmic or nuclear tumor tissue stains.

MGO has significant selectivity for malignant proliferating cells. The proliferation/apoptosis is progressive from LGD, HGD to invasive cancer. Previous study of colon cancer has shown possible effect of MGO on apoptosis and proliferation through cell line study $[12,18,19]$. MGO induces the inhibition of cell growth and toxicity of human leukemia 60 cells [42], inducing the accumulation of nucleic acid and protein adducts which leads to cell apoptosis [43]. Conversely, no significant inhibition of cell growth was found in mature neutrophils and lymphocytes (peripheral leucocytes) [42,43]. In addition, MGO treatment inhibited mitochondrial respiration of malignant cells, but had no inhibitory effect on the respiration of normal cells [32]. The anti-tumor effect of MGO is attributed to the inactivation of glyceraldehyde 3-phosphate dehydrogenase (GAPDH), which plays an important role in the high glycolytic capacity of malignant cells [44]. However, tumor growth was inhibited by single or continuous MGO administration in rodents inoculated with tumor cells $[19,45]$.

In contrast, MGO protects gastrointestinal cancer cells from apoptosis by increasing the anti-apoptotic activity of endogenous MGO-modified heat shock protein (HSP) 27, through the inhibition of caspase- 3 and 9 activation [46]. MGO-induced post-translational glycation of Hsp90 affects its activity with a consequent decrease in large tumor suppressor 1 (LATS1) expression, thereby promoting cancer cell growth and proliferation [47]. The accumulation of MGO adducts (e.g., argypirimidine) is found to be positively correlated with primary tumor staging, and the degree of dicarbonyl-induced stress is associated with CRC tumor aggressiveness [12]. MGO administration produces low-grade carbonyl stress that can lead to inflammation and oxidative stress, which is responsible for the deterioration of chemically induced colonic preneoplastic lesions in mice with colon cancer. Additionally, MGO induces colon cancer isograft growth by enhancing the expression/activation of proteins related to cell survival, proliferation, migration, and invasion [18].

MGO is a key contributor to diabetes-related complications and diabetes mellitus is a known risk factor for CRC [48]. Abnormal serum LDL/HDL ratio and fecal bile acid levels was reported exposure to MGO increased in azoxymethane-induced mice, which may play important roles in promoting CRC [18]. Metformin, typically used as a clinical anti-diabetic agent, can lower systemic MGO levels in a dose-dependent manner and $\mathrm{h}$ reduces the risk of CRC $[49,50]$. Plasma MGO levels are correlated with some systemic diseases, including diabetes [51], hypertension [52], renal failure [53] and septic shock [54]. We found that tissue MGO levels did not correlate with diabetes, smoking, or other underlying diseases; however, the case numbers are limited, and further investigation is necessary. Age is a risk factor for CRC and the incidence of CRC is higher among older adults [55]. However, 
our results indicated that MGO levels in colorectal tumor and peritumor tissue were not associated with age but rather to cancer grade or stage. In addition, we found that tissue MGO levels might be a reliable marker for cancer oncogenesis. These results suggest that MGO may promote CRC; however, no reliable epidemiological data has associated systemic or tissue MGO levels with CRC or compared MGO levels in CRC and precancerous lesions.

The main limitation of our study is that, although we observed higher MGO levels in peritumor tissue than in tumor tissue, we did not harvest tissue located further from the tumor tissue, and therefore could not determine whether MGO levels would be different in normal tissue distant to the tumor. Hence, a more comprehensive analysis with tissue harvested from different areas of the colon is needed. Moreover, we did not examine the prognostic effect of MGO levels in tumor or peritumor tissue since our cohort only consisted of patients with precancerous and cancerous lesions. The survival of the patients with precancerous lesions was high and the local recurrence was low after lesion resection via colonoscopy. In this study, precancerous lesion growth in other sections of the colon was also very rare; thus, a larger sample size is required to establish any prognostic effect.

\section{Conclusions}

This is the first study to demonstrate that MGO levels gradually increased along with the different stages of CRC tumor tissue progression (LGD, HGD, and IC). Moreover, we found that MGO levels were higher in peritumor tissues than in tumor tissues.

Supplementary Materials: The following are available online at https:/ / www.mdpi.com/article/10 $.3390 /$ life11121319/s1, Table S1: Precision and accuracy of methylglyoxal determination method in human colon samples $(\mathrm{n}=3)$.

Author Contributions: Conceptualization, C.-K.C., J.-A.L., P.-Y.T., K.-F.T. and P.-C.Y.; software, H.-Y.Y.; formal analysis, H.-Y.Y., K.-S.L. and C.-K.C.; investigation, C.-K.C.; resources, C.-K.C.; data curation, C.-K.C., P.-Y.T. and P.-C.Y.; writing-original draft preparation, C.-K.C., P.-C.Y. and T.-H.C.; writing-review and editing, C.-K.C., P.-C.Y., T.-H.C. and C.-Y.C.; supervision, C.-K.C.; project administration, C.-K.C.; funding acquisition, C.-K.C. and J.-A.L. All authors have read and agreed to the published version of the manuscript.

Funding: This research was funded by the Department of Research of Ditmanson Medical Foundation Chia-Yi Christian Hospital (grant number R105-20), and the Ministry of Science and Technology, Taiwan (grant number MOST 109-2320-B-038-037-).

Institutional Review Board Statement: The study was conducted according to the guidelines of the Declaration of Helsinki and approved by the Institutional Review Board of of Chia-Yi Christian Hospital (protocol code 102057).

Informed Consent Statement: Not applicable.

Data Availability Statement: The data presented in this study are available on request from the corresponding author.

Acknowledgments: The authors thank Wen-Chuang Wang for performing the pathological analysis.

Conflicts of Interest: The authors declare no conflict of interest.

\section{References}

1. World Health Organization. The Global Cancer Observatory. Available online: http://gco.iarc.fr/today/data/factsheets/ cancers/39-All-cancers-fact-sheet.pdf (accessed on 7 April 2021).

2. Ikeda, Y.; Mori, M.; Shibahara, K.; Iwashita, A.; Haraguchi, Y.; Saku, M. The role of adenoma for colorectal cancer development: Differences in the distribution of adenoma with low-grade dysplasia, high-grade dysplasia, and cancer that invades the submucosa. Surgery 2002, 131, S105-S108. [CrossRef]

3. Terzic, J.; Grivennikov, S.; Karin, E.; Karin, M. Inflammation and colon cancer. Gastroenterology 2010, 138, 2101-2114. [CrossRef] [PubMed]

4. Sawicki, T.; Ruszkowska, M.; Danielewicz, A.; Niedzwiedzka, E.; Arlukowicz, T.; Przybylowicz, K.E. A Review of Colorectal Cancer in Terms of Epidemiology, Risk Factors, Development, Symptoms and Diagnosis. Cancers 2021, 13, 2025. [CrossRef] [PubMed] 
5. Schalkwijk, C.G.; Stehouwer, C.D.A. Methylglyoxal, a Highly Reactive Dicarbonyl Compound, in Diabetes, Its Vascular Complications, and Other Age-Related Diseases. Physiol. Rev. 2020, 100, 407-461. [CrossRef] [PubMed]

6. Turk, Z.; Cavlovic-Naglic, M.; Turk, N. Relationship of methylglyoxal-adduct biogenesis to LDL and triglyceride levels in diabetics. Life Sci. 2011, 89, 485-490. [CrossRef]

7. Rabbani, N.; Thornalley, P.J. Methylglyoxal, glyoxalase 1 and the dicarbonyl proteome. Amino Acids 2012, 42, 1133-1142. [CrossRef]

8. Nedic, O.; Rattan, S.I.; Grune, T.; Trougakos, I.P. Molecular effects of advanced glycation end products on cell signalling pathways, ageing and pathophysiology. Free Radic. Res. 2013, 47 (Suppl. 1), 28-38. [CrossRef]

9. Nigro, C.; Leone, A.; Fiory, F.; Prevenzano, I.; Nicolo, A.; Mirra, P.; Beguinot, F.; Miele, C. Dicarbonyl Stress at the Crossroads of Healthy and Unhealthy Aging. Cells 2019, 8, 749. [CrossRef] [PubMed]

10. Miyazawa, N.; Abe, M.; Souma, T.; Tanemoto, M.; Abe, T.; Nakayama, M.; Ito, S. Methylglyoxal augments intracellular oxidative stress in human aortic endothelial cells. Free Radic. Res. 2010, 44, 101-107. [CrossRef]

11. Liu, B.F.; Miyata, S.; Hirota, Y.; Higo, S.; Miyazaki, H.; Fukunaga, M.; Hamada, Y.; Ueyama, S.; Muramoto, O.; Uriuhara, A.; et al. Methylglyoxal induces apoptosis through activation of p38 mitogen-activated protein kinase in rat mesangial cells. Kidney Int. 2003, 63, 947-957. [CrossRef]

12. Chiavarina, B.; Nokin, M.J.; Bellier, J.; Durieux, F.; Bletard, N.; Sherer, F.; Lovinfosse, P.; Peulen, O.; Verset, L.; Dehon, R.; et al. Methylglyoxal-Mediated Stress Correlates with High Metabolic Activity and Promotes Tumor Growth in Colorectal Cancer. Int. J. Mol. Sci. 2017, 18, 213. [CrossRef]

13. Ranganathan, S.; Tew, K.D. Analysis of glyoxalase-I from normal and tumor tissue from human colon. Biochim. Biophys. Acta 1993, 1182, 311-316. [CrossRef]

14. Rabbani, N.; Xue, M.; Weickert, M.O.; Thornalley, P.J. Multiple roles of glyoxalase 1-mediated suppression of methylglyoxal glycation in cancer biology-Involvement in tumour suppression, tumour growth, multidrug resistance and target for chemotherapy. Semin. Cancer Biol. 2018, 49, 83-93. [CrossRef]

15. Bellahcene, A.; Nokin, M.J.; Castronovo, V.; Schalkwijk, C. Methylglyoxal-derived stress: An emerging biological factor involved in the onset and progression of cancer. Semin. Cancer Biol. 2018, 49, 64-74. [CrossRef] [PubMed]

16. Vander Heiden, M.G.; Cantley, L.C.; Thompson, C.B. Understanding the Warburg effect: The metabolic requirements of cell proliferation. Science 2009, 324, 1029-1033. [CrossRef] [PubMed]

17. Ravichandran, M.; Priebe, S.; Grigolon, G.; Rozanov, L.; Groth, M.; Laube, B.; Guthke, R.; Platzer, M.; Zarse, K.; Ristow, M. Impairing L-Threonine Catabolism Promotes Healthspan through Methylglyoxal-Mediated Proteohormesis. Cell Metab. 2018, 27, 914-925. [CrossRef]

18. Lin, J.A.; Wu, C.H.; Yen, G.C. Methylglyoxal displays colorectal cancer-promoting properties in the murine models of azoxymethane and CT26 isografts. Free Radic. Biol. Med. 2018, 115, 436-446. [CrossRef]

19. He, T.; Zhou, H.; Li, C.; Chen, Y.; Chen, X.; Li, C.; Mao, J.; Lyu, J.; Meng, Q.H. Methylglyoxal suppresses human colon cancer cell lines and tumor growth in a mouse model by impairing glycolytic metabolism of cancer cells associated with down-regulation of c-Myc expression. Cancer Biol. Ther. 2016, 17, 955-965. [CrossRef] [PubMed]

20. Chen, Y.; Fang, L.; Li, G.; Zhang, J.; Li, C.; Ma, M.; Guan, C.; Bai, F.; Lyu, J.; Meng, Q.H. Synergistic inhibition of colon cancer growth by the combination of methylglyoxal and silencing of glyoxalase I mediated by the STAT1 pathway. Oncotarget 2017, 8 , 54838-54857. [CrossRef] [PubMed]

21. Chen, Y.; Fang, L.; Zhang, J.; Li, G.; Ma, M.; Li, C.; Lyu, J.; Meng, Q.H. Blockage of Glyoxalase I Inhibits Colorectal Tumorigenesis and Tumor Growth via Upregulation of STAT1, p53, and Bax and Downregulation of c-Myc and Bcl-2. Int. J. Mol. Sci. 2017, 18, 570. [CrossRef]

22. Pimentel-Nunes, P.; Dinis-Ribeiro, M.; Ponchon, T.; Repici, A.; Vieth, M.; De Ceglie, A.; Amato, A.; Berr, F.; Bhandari, P.; Bialek, A.; et al. Endoscopic submucosal dissection: European Society of Gastrointestinal Endoscopy (ESGE) Guideline. Endoscopy 2015, 47, 829-854. [CrossRef] [PubMed]

23. Edge, S.B.; Byrd, D.R.; Compton, C.C. American Joint Committee on Cancer (AJCC) Cancer Staging Manual, 7th ed.; Fritz, A.G., Greene, F.L., Trotti, A., Eds.; Springer: New York, NY, USA, 2010.

24. Brown, K.G.M.; Solomon, M.J.; Mahon, K.; O'Shannassy, S. Management of colorectal cancer. BMJ 2019, 366, 14561. [CrossRef]

25. Ferlitsch, M.; Moss, A.; Hassan, C.; Bhandari, P.; Dumonceau, J.M.; Paspatis, G.; Jover, R.; Langner, C.; Bronzwaer, M.; Nalankilli, K.; et al. Colorectal polypectomy and endoscopic mucosal resection (EMR): European Society of Gastrointestinal Endoscopy (ESGE) Clinical Guideline. Endoscopy 2017, 49, 270-297. [CrossRef]

26. Hamilton, S.R.; Bosman, F.T.; Boffeta, P.; Ilyas, M. Carcinoma of the colon and rectum. In WHO Classification of Tumours of the Digestive System, 4th ed.; Bozman, F.T., Carneiro, F., Hruban, R.H., Theise, N.D., Eds.; International Agency for Research on Cancer (IARC): Lyon, France, 2010; pp. 134-146.

27. Schlemper, R.J.; Riddell, R.H.; Kato, Y.; Borchard, F.; Cooper, H.S.; Dawsey, S.M.; Dixon, M.F.; Fenoglio-Preiser, C.M.; Flejou, J.F.; Geboes, K.; et al. The Vienna classification of gastrointestinal epithelial neoplasia. Gut 2000, 47, 251-255. [CrossRef] [PubMed]

28. Espinosa-Mansilla, A.; Duran-Meras, I.; Salinas, F. High-performance liquid chromatographic-fluorometric determination of glyoxal, methylglyoxal, and diacetyl in urine by prederivatization to pteridinic rings. Anal. Biochem. 1998, 255, 263-273. [CrossRef]

29. Srivastava, A.; Lauwers, G.Y. Gastric epithelial dysplasia: The Western perspective. Dig. Liver Dis. 2008, 40, 641-649. [CrossRef] [PubMed] 
30. Di Gregorio, C.; Morandi, P.; Fante, R.; De Gaetani, C. Gastric dysplasia. A follow-up study. Am. J. Gastroenterol. 1993, 88, 1714-1719. [PubMed]

31. Fertitta, A.M.; Comin, U.; Terruzzi, V.; Minoli, G.; Zambelli, A.; Cannatelli, G.; Bodini, P.; Bertoli, G.; Negri, R.; Brunati, S.; et al. Clinical significance of gastric dysplasia: A multicenter follow-up study. Endoscopy 1993, 25, 265-268. [CrossRef] [PubMed]

32. Yamada, H.; Ikegami, M.; Shimoda, T.; Takagi, N.; Maruyama, M. Long-term follow-up study of gastric adenoma/dysplasia. Endoscopy 2004, 36, 390-396. [CrossRef] [PubMed]

33. Rugge, M.; Cassaro, M.; Di Mario, F.; Leo, G.; Leandro, G.; Russo, V.M.; Pennelli, G.; Farinati, F. The long term outcome of gastric non-invasive neoplasia. Gut 2003, 52, 1111-1116. [CrossRef]

34. Park, S.Y.; Jeon, S.W.; Jung, M.K.; Cho, C.M.; Tak, W.Y.; Kweon, Y.O.; Kim, S.K.; Choi, Y.H. Long-term follow-up study of gastric intraepithelial neoplasias: Progression from low-grade dysplasia to invasive carcinoma. Eur. J. Gastroenterol. Hepatol. 2008, 20, 966-970. [CrossRef]

35. De Jong, M.E.; Kanne, H.; Nissen, L.H.C.; Drenth, J.P.H.; Derikx, L.; Hoentjen, F. Increased risk of high-grade dysplasia and colorectal cancer in inflammatory bowel disease patients with recurrent low-grade dysplasia. Gastrointest. Endosc. 2020, 91, 1334-1342. [CrossRef]

36. Muthusami, S.; Ramachandran, I.K.; Babu, K.N.; Krishnamoorthy, S.; Guruswamy, A.; Queimado, L.; Chaudhuri, G.; Ramachandran, I. Role of Inflammation in the Development of Colorectal Cancer. Endocr. Metab. Immune Disord. Drug Targets 2021, 21, 77-90. [CrossRef]

37. Jess, T.; Loftus, E.V., Jr.; Harmsen, W.S.; Zinsmeister, A.R.; Tremaine, W.J.; Melton, L.J., 3rd; Munkholm, P.; Sandborn, W.J. Survival and cause specific mortality in patients with inflammatory bowel disease: A long term outcome study in Olmsted County, Minnesota, 1940-2004. Gut 2006, 55, 1248-1254. [CrossRef]

38. Leone, A.; Nigro, C.; Nicolo, A.; Prevenzano, I.; Formisano, P.; Beguinot, F.; Miele, C. The Dual-Role of Methylglyoxal in Tumor Progression-Novel Therapeutic Approaches. Front. Oncol. 2021, 11, 645686. [CrossRef]

39. DeBerardinis, R.J.; Chandel, N.S. We need to talk about the Warburg effect. Nat. Metab. 2020, 2, 127-129. [CrossRef]

40. Liberti, M.V.; Locasale, J.W. The Warburg Effect: How Does it Benefit Cancer Cells? Trends Biochem. Sci. 2016, 41, 211-218. [CrossRef]

41. Lin, J.A.; Wu, C.H.; Lu, C.C.; Hsia, S.M.; Yen, G.C. Glycative stress from advanced glycation end products (AGEs) and dicarbonyls: An emerging biological factor in cancer onset and progression. Mol. Nutr. Food Res. 2016, 60, 1850-1864. [CrossRef] [PubMed]

42. Ayoub, F.M.; Allen, R.E.; Thornalley, P.J. Inhibition of proliferation of human leukaemia 60 cells by methylglyoxal in vitro. Biochem. Soc. Trans. 1993, 21, 168S. [CrossRef] [PubMed]

43. Kang, Y.; Edwards, L.G.; Thornalley, P.J. Effect of methylglyoxal on human leukaemia 60 cell growth: Modification of DNA G1 growth arrest and induction of apoptosis. Leuk. Res. 1996, 20, 397-405. [CrossRef]

44. Halder, J.; Ray, M.; Ray, S. Inhibition of glycolysis and mitochondrial respiration of Ehrlich ascites carcinoma cells by methylglyoxal. Int. J. Cancer 1993, 54, 443-449. [CrossRef]

45. Thornalley, P.J. Advances in glyoxalase research. Glyoxalase expression in malignancy, anti-proliferative effects of methylglyoxal, glyoxalase I inhibitor diesters and S-D-lactoylglutathione, and methylglyoxal-modified protein binding and endocytosis by the advanced glycation endproduct receptor. Crit. Rev. Oncol. Hematol. 1995, 20, 99-128. [CrossRef]

46. Oya-Ito, T.; Naito, Y.; Takagi, T.; Handa, O.; Matsui, H.; Yamada, M.; Shima, K.; Yoshikawa, T. Heat-shock protein 27 (Hsp27) as a target of methylglyoxal in gastrointestinal cancer. Biochim. Biophys. Acta 2011, 1812, 769-781. [CrossRef]

47. Nokin, M.J.; Durieux, F.; Peixoto, P.; Chiavarina, B.; Peulen, O.; Blomme, A.; Turtoi, A.; Costanza, B.; Smargiasso, N.; Baiwir, D.; et al. Methylglyoxal, a glycolysis side-product, induces Hsp90 glycation and YAP-mediated tumor growth and metastasis. elife 2016, 5, e19375. [CrossRef] [PubMed]

48. Larsson, S.C.; Orsini, N.; Wolk, A. Diabetes mellitus and risk of colorectal cancer: A meta-analysis. J. Natl. Cancer Inst. 2005, 97, 1679-1687. [CrossRef]

49. He, X.K.; Su, T.T.; Si, J.M.; Sun, L.M. Metformin Is Associated With Slightly Reduced Risk of Colorectal Cancer and Moderate Survival Benefits in Diabetes Mellitus: A Meta-Analysis. Medicine 2016, 95, e2749. [CrossRef]

50. Beisswenger, P.J.; Howell, S.K.; Touchette, A.D.; Lal, S.; Szwergold, B.S. Metformin reduces systemic methylglyoxal levels in type 2 diabetes. Diabetes 1999, 48, 198-202. [CrossRef] [PubMed]

51. Lu, J.; Randell, E.; Han, Y.; Adeli, K.; Krahn, J.; Meng, Q.H. Increased plasma methylglyoxal level, inflammation, and vascular endothelial dysfunction in diabetic nephropathy. Clin. Biochem. 2011, 44, 307-311. [CrossRef]

52. Ogawa, S.; Nakayama, K.; Nakayama, M.; Mori, T.; Matsushima, M.; Okamura, M.; Senda, M.; Nako, K.; Miyata, T.; Ito, S. Methylglyoxal is a predictor in type 2 diabetic patients of intima-media thickening and elevation of blood pressure. Hypertension 2010, 56, 471-476. [CrossRef]

53. Lapolla, A.; Flamini, R.; Lupo, A.; Arico, N.C.; Rugiu, C.; Reitano, R.; Tubaro, M.; Ragazzi, E.; Seraglia, R.; Traldi, P. Evaluation of glyoxal and methylglyoxal levels in uremic patients under peritoneal dialysis. Ann. N. Y. Acad. Sci. 2005, 1043, 217-224. [CrossRef] [PubMed]

54. Brenner, T.; Fleming, T.; Uhle, F.; Silaff, S.; Schmitt, F.; Salgado, E.; Ulrich, A.; Zimmermann, S.; Bruckner, T.; Martin, E.; et al. Methylglyoxal as a new biomarker in patients with septic shock: An observational clinical study. Crit. Care 2014, 18, 683. [CrossRef] [PubMed]

55. Nee, J.; Chippendale, R.Z.; Feuerstein, J.D. Screening for Colon Cancer in Older Adults: Risks, Benefits, and When to Stop. Mayo Clin. Proc. 2020, 95, 184-196. [CrossRef] [PubMed] 